\title{
Effect of Pneumoperitoneum on Renal Function and Physiology in Patients Undergoing Robotic Renal Surgery
}

\author{
Serena Sodha ${ }^{a} \quad$ Scarlet Nazarian ${ }^{b} \quad$ James M. Adshead ${ }^{b} \quad$ Nikhil Vasdev $^{b}$ \\ Gowrie Mohan-S ${ }^{b}$ \\ aDepartment of Anaesthetics; and ' ${ }^{\mathrm{H}}$ ertfordshire and South Bedfordshire Robotic Urological Cancer Centre, Lister Hospital, Stevenage, UK
}

\section{Key Words}

Pneumoperitoneum • Renal blood flow • Renal dysfunction• Neuroendocrine $\cdot$ Oxidative stress

\begin{abstract}
Laparoscopic and minimally-invasive robotic access has transformed the delivery of urological surgery. While associated with numerous desirable outcomes including shorter post-operative stay and faster return to preoperative function, these techniques have also been associated with increased morbidity such as reduced renal blood flow and post-operative renal dysfunction. The mechanisms leading to these renal effects complex and multifactorial, and have not been fully elucidated. However they are likely to include direct effects from raised intra-abdominal pressure, and indirect effects secondary to carbon dioxide absorption, neuroendocrine factors and tissue damage from oxidative stress. This review summarises these factors, and highlights the need for further work in this area, to direct novel therapies and guide alterations in technique with the aim of reducing renal dysfunction post-laparoscopic and robotic surgery.
\end{abstract}

Copyright @ 2015 S. Karger AG, Basel

KARGER

Fax +4161306 1234

E-Mail karger@karger.ch

www.karger.com
(C) 2015 S. Karger AG, Basel

1015-9770/14/0091-0001\$38.00/0

Accessible online at:

www.karger.com/cur

\section{Introduction}

Robotic renal surgery has transformed the delivery of reconstructive and extirpative urological procedures. In contrast to open access, this approach is associated with lower morbidity, decreased pain, shorter postoperative hospital stay, faster return to preoperative function, and superior cosmesis $[1,2]$. Carbon dioxide $\left(\mathrm{CO}_{2}\right)$ is the gas most commonly used for insufflation, although inert gases such as helium and argon have also been used. $\mathrm{CO}_{2}$ however, as well as being non-combustible, and highly soluble in blood making gas embolism unlikely, also has the advantage of low cost [3].

Pneumoperitoneum, although generally considered essential for adequate exposure in robotic surgery, is associated with significant direct and indirect effects on renal physiology. In particular, at a pressure of above 10 $\mathrm{mmHg}$, pneumoperitoneum has been shown to produce reduced renal blood flow, renal dysfunction and a transient oliguria [2-5].

Demyttenaere et al. [6] in 2007 conducted a systematic review on the effect of pneumoperitoneum on renal perfusion and function. They first looked at the reduction of renal blood flow associated with pneumoperitoneum, and found that of the 20 studies examined, 17 demonstrated a reduction in renal blood flow. A number of

Nikhil Vasdev

Hertfordshire and South Bedfordshire Robotic Urological Cancer Centre

Lister Hospital

Stevenage (UK)

E-Mail nikhilvasdev@doctors.org.uk 
factors influenced the extent to which blood flow fell. These were the pressure used for insufflation, positioning (worst in the head up position), and the fluid status of the patient. It was not affected by the gas used. Twenty of the 25 studies they found looking at the effect on renal function found a decrease in function in response to pneumoperitoneum. The decrease appeared to be temporary however, with function returning to normal after a variable time.

Exact mechanisms of these renal effects of pneumoperitoneum have not been fully determined despite much research, but are likely to include direct effect from raised intra-abdominal pressure, and indirect effects from $\mathrm{CO}_{2}$ absorption, neuroendocrine factors and tissue damage secondary to oxidative stress.

Whereas in young healthy patients, the effects of these may be minimal and transient due to physiological compensation and buffering mechanisms, in the elderly population, with a limited physiological reserve and possible underlying renal dysfunction, these effects on renal physiology may be clinically significant.

While initially only young, fit patients were selected, with advancing technology and surgical familiarity and skill in robotic techniques are increasingly used in patients deemed to be unfit for major open surgery. It is therefore more and more likely that the population presenting for surgery have significant comorbidities.

\section{Direct Effects of Pneumoperitoneum}

A direct effect of raised intra-abdominal pressure secondary to pneumoperitoneum is an increase in renal vascular resistance due to compression of the renal vasculature. There is also direct compression on the renal parenchyma [7].

In addition to reduced renal blood flow secondary to increased vascular resistance, renal perfusion pressure (a second factor in the Hagen-Poiseuille equation) is reduced during pneumoperitoneum secondary to a reduction in cardiac output. This occurs due to direct compression to the inferior vena cava leading to reduced preload and therefore a lower stroke volume. Compensatory mechanisms such as the release of stress hormones including catecholamines leading to an increase systemic vascular resistance, heart rate and contractility, may be compromised in an elderly population undergoing robotic urological surgery. Receptor downregulation associated with age is often combined with a stiff and hypertrophied left ventricle. During pneumoperitoneum the additional burdens of an increase in afterload, a shortened diastolic time secondary to tachycardia leading to insufficient ventricular relaxation and filling, and inadequate perfusion pressure in already constricted coronary arteries all lead to an increasing risk of decompensation and inadequate organ perfusion.

\section{Indirect Effects of Pneumoperitoneum}

However, hemodynamic alterations do not alone explain the changes in renal blood flow and function secondary to pneumoperitoneum. As a result of the direct compression described, renal autoregulation results in the stimulation of the renin-angiotensin-aldosterone system (RAAS), with increasing renin release and subsequent aldosterone secretion. Secondly, neuroendocrine responses result in the excretion of anti-diuretic hormone. The result is salt and water retention with oliguria, and a vicious cycle of renal cortical vasoconstriction leading to further activation the RAAS.

Aside from the RAAS, other hormonal factors have also been proposed as mechanisms to explain renal dysfunction associated with raised intra-abdominal pressure. Abassi at el. [8] investigated the involvement of endothelin-1, a potent vasoconstrictor of which the kidney is a target organ and a major source, and nitric oxide (NO) systems. They successfully demonstrated involvement of both systems in pneumoperitoneum-associated changes in renal hemodynamics. They found that blockade of endothelin or NO systems aggravate the pneumoperitoneum-induced renal hypoperfusion and oliguria, while pretreatment with nitroglycerin substantially attenuates the adverse effects of elevated intra-abdominal pressure on renal function.

In addition to neuroendocrine factors, renal damage may be initiated by pneumoperitoneum-associated ischemia-reperfusion, in which oxidants are posed to play a role. The rise in intra-abdominal pressure leads to alterations in renal blood flow as already described. After desufflation, reperfusion occurs when renal blood flow normalises, which increases oxidative stress due to an imbalance between oxidants and anti-oxidants, leading to tissue damage [4].

Koury et al. [9] applied pneumoperitoneal pressure to isolated perfused kidney and demonstrated an association with renal apoptosis. This rapidly induced structural renal damage was oxidant dependent and was attenuated by antioxidants. The role of antioxidants to prevent renal damage is supported by Seguro et al. [4]. They demon- 
strated that in $\mathrm{N}$-acetylcysteine-treated rats, a complete protection against glomerular filtration rate drops was observed 24 and 72 hours following 3 hours of pneumoperitoneum, associated with a decrease in serum thiobarbituric acid reactive substances, which were used to evaluate oxidative stress.

Whether antioxidants have a role in the prevention of pneumoperitoneum induced renal dysfunction in humans needs to be further investigated.

In the role of oxidative stress, neuroendocrine factors and cardiovascular factors, hypercarbia and acidosis have been proposed to play a role. While $\mathrm{CO}_{2}$ 's ready solubility in blood is advantageous in making gas embolism unlikely, it is also absorbed very rapidly from the peritoneal cavity into the circulation. From here it can only be excreted through the lungs, and therefore a compensatory hyperventilation is necessary to avoid hypercarbia and respiratory acidosis. However, during prolonged surgery, with raised intra-abdominal pressure and a Trendelenberg position, attempts at increasing ventilation may be impeded. There is cephalad displacement of the diaphragm, and reduced diaphragmatic motility, as well as increasing ventilation-perfusion mismatch. This occurs in a population with likely already compromised cardio-respiratory function. Hypercarbia can cause direct actions on the cardiovascular system such as negative inotropy, sensitisation of the myocardium to arrhythmogenic effects of catecholamines, and systemic vasodilatation. In addition, indirect actions on the cardiovascular system also occur for example via sympathoadrenal stimulation, leading to tachycardia and vasoconstriction [3]. The precise role of $\mathrm{CO}_{2}$ in renal impairment secondary to oxidative stress and other neuroendocrine mechanisms remains unclear. McDougall et al. [10] have demonstrated pressure-dependent $\mathrm{CO}_{2}$ absorption through the peritoneal surface, which was not seen with argon insufflation. Increased renin activity in dogs following $\mathrm{CO}_{2}$, but not helium, insufflation has also been established [11].

With technological advances, and increasing surgical familiarity and skill using robotic techniques, further changes in surgical approach to urological procedures are becoming widespread, such as the retroperitoneal approach to partial nephrectomy. Data so far is limited but encouraging, particularly in relation to operative time, postoperative analgesia requirements and return of bowel function. Whether associated with an improvement in outcomes with relation to renal function is yet to be elucidated, and we await further trials with interest.

Patient with ischaemic heart disease, remote ischaemic conditioning may protect the myocadium against acute ischaemia-reperfusion injury, preserving cardiac func-

Effect of Pneumoperitoneum on Renal Function and Physiology in Robotic Renal Surgery tion. Remote ischaemic conditioning involves occlusion and reflow of blood to an organ or tissue. This generate cardioprotective signal in the conditioned remote organ or tissue and conveys to the heart. This activates intracellular signalling pathways within the heart that mediate the cardioprotective effect [12]. McClanahan et al. [13] demonstrated that 10 minutes of occlusion and reflow of the renal artery could reduce infarct size induced by 30 minutes ligation and reperfusion of coronary artery.

Furthermore, the effects of prolonged warm ischaemia during robotic renal surgery, in addition to pneumoperitoneum should be taken into consideration when assessing renal function. During a robotic partial nephrectomy, warm ischaemic time (WIT) and its effect on renal function has been the focus of many recent studies due to its modifiable feature. Choi et al. identified that during robot-assisted surgery under pneumoperitoneum, a WIT of $>28$ minutes caused a significantly greater decrease in glomerular filtration rate of the affected kidney compared to the contralateral healthy kidney [14]. More recently, Porpiglia et al. [15] used effective renal plasma flow as a parameter for renal function analysis in relation to WIT. The study concluded that a WIT of $>25$ minutes is associated with a significant decline in renal function and should not be exceeded during robotic surgery.

A prolonged WIT has been associated with long-term damage to the affected kidney. In addition to the link between WIT and acute kidney injury, it has been suggested that a WIT of $>25$ minutes is associated with chronic kidney disease stage IV [16]. It must therefore be questioned whether the joint effect of pneumoperitoneum and WIT during robotic surgery leads to an even greater deterioration of renal function and possible irreversible damage to the kidney.

From comparisons made between open surgery, where pneumoperitoneum is eliminated as a contributing factor, and robotic procedures, no difference in renal function recovery has been found [17]. However, as more complex robotic renal procedures are undertaken, the duration of warm ischaemia rises in these procedures. Thompson et al. [18] have shown that open surgery is associated with an overall shorter ischaemia time, thus highlighting that open surgery leads to a less significant decline in renal function for these patients.

It must also be noted, that WIT has been compared with cold ischaemia time. WIT of $>25$ minutes causes long-term ( $>6$ months) damage to the kidney, whilst cold ischaemia time of up to 58 minutes prevents ischaemic injury [19]. A collaborative literature review has concluded that it is vital to minimise WIT intra-operatively 
in order to prevent deterioration in post-operative renal function. In cases where prolonged ischaemia time is anticipated, cold ischaemia should be favoured [20].

\section{Conclusion}

The effects of pneumoperitoneum on renal function and physiology are complex and multifactorial. The molecular mechanisms behind these renal consequences have yet to be fully elucidated, although direct compressive, cardiovascular, oxidative and neurohormonal responses have all been posed to play a role. Further work is needed in order to establish whether targeting the cardiovascular system with intravascular loading and inotropes is key to maintaining renal function, whether inhibiting the neuroendocrine response should be considered, for example with esmolol to inhibit renin release and pressor response to pneumoperitoneum, or whether antioxidants could also play a role.

\section{References}

1 Freitas PF, Durães LC, Carvalho FA, Duarte SA, Carneiro FP, Sousa JB: Effects of pneumoperitoneum with carbon dioxide and helium on renal function and morphology in rats. Acta Cir Bras 2013;28:494-498.

2 Khoury W, Jakowlev K, Fein A, Orenstein H, Nakache R, Weinbroum AA: Renal apoptosis following carbon dioxide pneumoperitoneum in a rat model. J Urol 2008;180:1554-1558.

3 Gutt CN, Oniu T, Mehrabi A, Schemmer P, Kashfi A, Kraus T, Büchler MW: Circulatory and respiratory complications of carbon dioxide insufflation. Dig Surg 2004;21:95-105.

4 Seguro AC, Poli de Figueiredo LF, Shimizu MH: N-acetylcysteine (NAC) protects against acute kidney injury (AKI) following prolonged pneumoperitoneum in the rat. $\mathrm{J}$ Surg Res 2012;175:312-315.

5 Wiesenthal JD, Fazio LM, Perks AE, Blew BD, Mazer D, Hare G, Honey RJ, Pace KT: Effect of pneumoperitoneum on renal tissue oxygenation and blood flow in a rat model. Urology 2011;77:1508.e9-15.

6 Demyttenaere S, Feldman LS, Fried GM: Effect of pneumoperitoneum on renal perfusion and function: a systematic review. Surg Endosc 2007;21:152-160.

7 Vasdev N, Poon AS, Gowrie-Mohan S, Lane T, Boustead G, Hanbury D, Adshead JM: The physiologic and anesthetic considerations in elderly patients undergoing robotic renal surgery. Rev Urol 2014;16:1-9.

8 Abassi Z, Bishara B, Karram T, Khatib S, Winaver J, Hoffman A: Adverse effects of pneumoperitoneum on renal function: involvement of the endothelin and nitric oxide systems. Am J Physiol Regul Integr Comp Physiol 2008;294:R842-850.
9 Khoury W, Weinbroum AA: Oxidants as important determinants of renal apoptosis during pneumoperitoneum: a study in an isolated perfused rat kidney model. Surg Endosc 2012;26:1417-1424.

10 McDougall EM, Monk TG, Wolf Jr JS, Hicks M, Clayman RV, Gardner S, Humphrey PA, Sharp T, Martin K: The effect of prolonged pneumoperitoneum on renal function in an animal model. J Am Coll Surg 1996;182:317328

11 Carmona M, Lopes RI, Borba M, Omokawa M, Naufal R, Miyaki K, Matsumura N, Vieira N, Pereira PR: Comparison of the effects of carbon dioxide and helium pneumoperitoneum on renal function. J Endourol 2008;22: 1077-1082.

12 Gho BC, Schoemaker RG, van den Doel MA, Duncker DJ, Verdouw PD: Myocardial protection by brief ischaemia in noncardiac tissue. Circulation 1996;94:2193-2200.

13 McClanahan TB, Nao BS, Wolke LJ, Martin BJ, Mertz TE, Gallagher KP: Brief renal occlusion and reperfusion reduces myocardial infarct size in rabbits. FASEB J 1993;7:A118.

14 Choi JD, Park JW, Choi JY, Kim HS, Jeong BC, Jeon SS, Lee HM, Choi HY, Seo SI: Renal damage caused by warm ischaemia during laparoscopic and robot-assisted partial nephrectomy: an assessment using Tc 99m-DTPA glomerular filtration rate. Eur Urol 2010;58:900-905.
15 Porpiglia F, Fiori C, Bertolo R, Angusti T, Piccoli GB, Podio V, Russo R: The effects of warm ischaemia time on renal function after laparoscopic partial nephrectomy in patients with normal contralateral kidney. World J Urol 2012;30:257-263.

16 Thompson RH, Lane BR, Lohse CM, Leibovich BC, Fergany A, Frank I, Gill IS, Blute ML, Campbell SC: Renal function after partial nephrectomy: effect of warm ischemia relative to quantity and quality of preserved kidney. Urology 2012;79:356-360.

17 Gill IS, Kavoussi LR, Lane BR, Blute ML, Babineau D, Colombo JR Jr, Frank I, Permpongkosol S, Weight CJ, Kaouk JH, Kattan MW, Novick AC: Comparison of 1,800 laparoscopic and open partial nephrectomies for single renal tumors. J Urol 2007;178:41-46.

18 Thompson RH, Leibovich BC, Lohse CM, Zincke H, Blute ML: Complications of contemporary open nephron sparing surgery: a single institution experience. J Urol 2005; 174:855-858.

19 Funahashi Y, Yoshino Y, Sassa N, Matsukawa Y, Takai S, Gotoh M: Comparison of warm and cold ischemia on renal function after partial nephrectomy. Urology 2014;84:14081412.

20 Volpe A, Blute ML, Ficarra V, Gill IS, Kutikov A, Porpiglia F, Rogers C, Touijer KA, Van Poppel H, Thompson RH: Renal ischemia and function after partial nephrectomy: a collaborative review of the literature. Eur Urol 2015;68:61-74. 